\title{
PHYSIOLOGICAL EFFECTS AND OPERATIONAL USE OF POSITIVE PRESSURE BREATHING FOR G-PROTECTION
}

\author{
Eckard GLASER ${ }^{1,2}$, Hanns-Christian GUNGA' ${ }^{1}$, Carla LEDDERHOS ${ }^{2}$ \\ ${ }^{1}$ Charité Berlin, Center for Space Medicine Berlin (ZWMB), Berlin, Germany \\ ${ }^{2}$ German Air Force Center for Aerospace Medicine, Fuerstenfeldbruck, Berlin, Germany
}

Source of support: Own sources

Author's address: Carla Ledderhos, German Air Force Center for Aerospace Medicine, Str.der Luftwaffe 322, 82256 Fürstenfeldbruck, e-mail: CarlaLedderhos@bundeswehr.org

\begin{abstract}
In preparation for a study, a MedLine search was conducted to review the status quo of positive pressure breathing for $G$ protection (PPG). Aside from protective clothing, positive pressure breathing is one of the central building blocks of today's anti-G measures. PPG has been covered by quite a few reviews. Since a definite review by Fong and Fan in 1997, a number of articles have been published. The topics covered reflect the effects of the new capabilities of 4th and higher generation fighter aircraft, such as the high onset-rates and the high sustained Gz-loads, and the need for further anti-G protection concepts. Furthermore, an old anti-G suit concept has been revived and emerged in recent publications. Positive pressure breathing for $\mathrm{Gz}$ protection is reviewed in comparison with anti-G-straining maneuvers (AGSM) with regard to pressure schedules and with respect to the composition of the inspired gas mixture. In addition, operational considerations are reviewed, covering aspects that contribute to the successful deployment of anti-G gear. Particular focus was put on the reduction of unwanted side effects of anti-G suits and PPG. The work available on this topic and new technology anti-G suits suggest more work to be done, in particular in the field of undesirable side effects on the health of the pilots.
\end{abstract}

Keywords: positive pressure breathing for G protection, PPG, Anti-G suits, Anti-G straining maneuvers

Figure: 1 - References: 100 - Full-text PDF: http://www.pjambp.com • Copyright (C) 2016 Polish Aviation Medicine Society, ul. Krasińskiego 54/56, 01-755 Warsaw, license WIML • Indexation: Index Copernicus, Polish Ministry of Science and Higher Education 


\section{INTRODUCTION}

Pilots require means that allow them to match or at least come close to matching the performance envelope of their aircraft. The point where the unassisted and unprotected pilot can be expected to do so has long since passed: fourth and higher generation fighter aircraft bring a new quality of exposure to acceleration forces to aircrews. Gz forces can be sustained much longer, and the onset and offset of these forces can be much brisker than in prior fighter aircraft. In an effort to ensure both short and long-term operational readiness of aircrews, an intensive search for new techniques capable of further increasing the G-tolerance began when the 4th generation of aircraft appeared in the 80ies. In this context, positive pressure breathing for $\mathrm{G}$ protection came more and more into focus.

Just as the name suggests, the term PPG describes a breathing process with externally controlled, continuous positive pressure used to protect the pilots against G-forces. The positive pressure is applied through a facemask continuously throughout the respiratory cycle. The applied positive breathing pressure is transmitted to the arterial system in the same manner as the pressure generated during an anti-G straining maneuver. The striking difference is the minimal voluntary effort required by the individual when positive pressure is applied.
PPG is accompanied by a number of additional measures like anti-G suits/trousers, usually a counterpressure vest, waistcoat or jerkin (in that case PPG is called "assisted or balanced PPG"), and occasionally surgical hoses or functionally equivalent gear covering the upper and lower arms $[14,32,55,69]$. The anti-G gear and procedures interact; they are usually employed in combination.

Initially, positive pressure breathing (PPB) was introduced into service in 1944 [44] to further increase the oxygen ceiling of aircrews and protect them from the effects of reduced $\mathrm{O} 2$ partial pressure of higher altitudes and, in the case of the potentially catastrophic, sudden failure of cabin pressurization at high altitudes. For fighter pilots in World War II, this was meant to be a tactical altitude advantage hence it was called pressure breathing for altitude protection (PBA).

Later on, this method (PPB) was also discovered to be capable of increasing the $G$ tolerance of airmen. Most likely the first experimental proof of this concept was provided by Lambert in 1944 [67,98]. Although historically introduced to increase the oxygen partial pressure at high altitudes, the use of positive pressure breathing has been extended to counteract the fatigue issue while performing the AGSM. PPG increases intrathoracic pressure through external pressure applied through the breathing mask.

\section{Work on PPG since 1960}

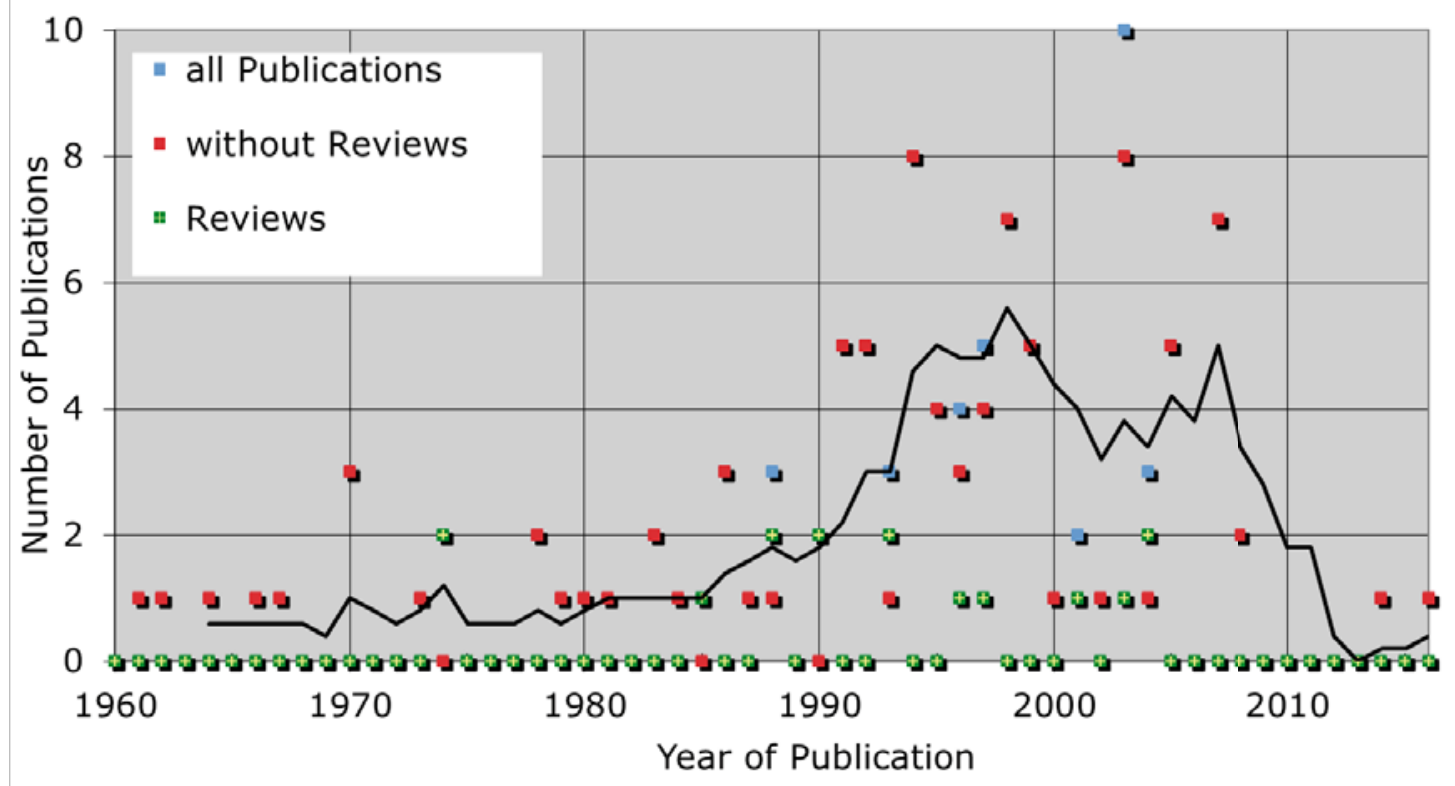

Fig. 1. Shows the distribution of frequency of the appearance of papers dealing with PPG over the years since the 1960 s. A noticeable increase can be attributed to the introduction of 4th generation aircraft into service. 
Today PPG is used in most nations to meet the demands of modern fighter aircraft. Fundamental investigations of the physiological consequences/ effects of positive pressure breathing on the circulatory and respiratory systems go back to the forties of the last century. At that time, they focused on the action of positive pressure breathing for altitude protection [12,29,44]. Therefore, only moderate levels of airway pressure were a subject matter of subject in those studies ( 4 inches of water to 12 inches of water $(30 \mathrm{cmH} 2 \mathrm{O}=23 \mathrm{mmHg}))$. The high sustained $\mathrm{Gz}$ capabilities of current highly maneuverable fighter aircraft require much higher airway pressures to the order ranging from $8.0 \mathrm{kPa}(=60 \mathrm{mmHg})$ to $10.7 \mathrm{kPa}(=80 \mathrm{mmHg})$. So the question arises whether the knowledge of the side effects of former times is still true today.

PPG is one of the key building blocks of today's anti-G measures. Since the appearance of two of the last reviews [41,67], a noticeable number of papers have been published.

The objective of this paper was to review, summarize and describe the results of the world literature search on PPG. By doing so, an overview of the recent work covering various aspects, including the fringe effects of positive pressure breathing will be presented.

For systematic reasons, this publication will first summarize the manifold aspects of PPG used alone or in combination with anti-G straining maneuvers (AGSM). In addition, the various PPG schedules used will be discussed and. last but not least, operational and health aspects will be reviewed.

\section{SOURCES}

A Medline search was conducted using a combination of terms, i.e. "Gz and Positive Pressure Breathing" (38 hits +1 hit in Chinese), "Gz and Atelectasis" (9 hits) and "Positive Pressure Breathing and G-Protection" (21 hits with few articles not found by the previous search term combinations). The search covered dates up to and including December 2016. Neither language nor date restrictions were set. A total of 51 different articles were found.

In addition, a search of the ASMA CD \# 2007 was conducted using the same search terms (17 hits). Abstracts for posters and presentations were omitted. Furthermore, a manual search of the AGARD and RTO archive was conducted. Review articles emerging from the search were screened for further publications. This revealed a number of additional hits that were directly or indirectly linked with this topic, ending up with a total of 100 different articles covering this topic and cited in this review.

The articles were divided into different groups. The criteria applied included the max. Gz-load, max. Gz-duration, applied PPG pressure, type of anti-G suit and measured parameters. The review shows the different approaches to PPG under high Gz loads.

All the articles found were considered; however, not all the articles found contributed to the particular focus of this review. These articles are hence not cited.

\section{PRINCIPAL FINDINGS}

\section{Enhancement of $\mathrm{Gz}$ Tolerance through PPG}

\section{Increasing G-duration tolerance (G-endurance tolerance) (G-time tolerance) with PPG}

Improved flight performance of aircraft has prompted the development of improved G-ensembles. The ability to increase G-endurance tolerance has been shown for many anti-G suits (COMBined Advanced Technology Enhanced Designed G-Ensemble (Combat EDGE), US Air Force Advanced Tactical Anti-G System (ATAGS), US Navy Enhanced Anti-G Lower Ensemble (EAGLE), Tactical Life Support System (TLSS), Swedish Anti-G Ensemble 39 (AGE-39), Extended-Coverage antiG Suit (ECGS) of the Finnish Air Force, etc.). All of them use PPG.

Although controversially described by some authors [71], it is predominantly agreed that PPG, assisted or not, increases the G-endurance of pilots $[2,35,40,58,62,81]$. A striking result was presented by Burns and Balldin [19]; assisted by PPG pressures of $50 \mathrm{mmHg}$ and $70 \mathrm{mmHg}$, the endurance of the pilots in simulated aerial combat maneuvers (SACM) just about doubled in comparison to the reference group wearing anti-G suits and performing AGSM.

These results were confirmed in another experiment [31]; durations of over $2 \frac{1}{2}$ minutes in SACM were achieved with PPG compared to less than $1 \frac{1}{2}$ minutes without PPG. It is interesting to note that higher pressure did not lead to better endurance.

One team [66] reported a case of up to $12 \frac{1 / 2}{2}$ minutes of SACM and 3 cases with over 9 minutes of SACM continuously using extended anti-G suits and PPG.

Experimental data supports the position stated in earlier publications: G-tolerance time increases 
with PPG in comparison to AGSM. Earlier pilot fatigue with AGSM is the common explanation for the differences $[2,19,62]$.

In addition to the increase of head level arterial blood pressure, G-time tolerance is improved by PPG due to its effect on the respiratory system. It reduces inspiratory resistance and increases overall lung breathing volume. Due to this, the gas exchange is improved and the fall in arterial oxygen saturation normally seen at accelerations of more than $+4 \mathrm{Gz}$ is reduced. Also, arterial oxygenation increases and the necessary effort to be generated by the aircrew is reduced [62]. However, in experiments aimed to further improve oxygenation by the administration of PPG together with increased $\mathrm{O} 2$ fractions, it was observed that higher $\mathrm{O} 2$ fractions do not necessarily lead to better oxygenation but to a higher degree of atelectasis $[36,41,61,89,90]$.

Furthermore, it could be shown that $G$ endurance is diminished when the pressure in extended coverage trousers was reduced $[65,66]$, whereas no change in the G-endurance could be observed when no chest counterpressure was used $[58,95,97]$.

In addition, Balldin and Siegborn [7] found no deterioration of $\mathrm{G}$-endurance in their heat stress experiments when using PPG.

\section{Increasing relaxed G-level tolerance (relaxed +Gz-intensity tolerance) with PPG}

PPG has been compared in various settings and using different benchmarks. One approach to show the effect of PPG is to measure the relaxed $+\mathrm{Gz}$ tolerance of individuals, with or without assistance. and with different anti-G suits. Burns [18] reported an average increase in relaxed $\mathrm{G}$ tolerance of up to $0.7 \mathrm{Gz}$, depending on the pressure schedule, for assisted PPG. This is less than he expected based on theoretical considerations. Also, Domaszuk [34,35] found PPG to improve the G tolerance, to different degrees, for all groups of test subjects. He reported increases of up to 2.2 $\mathrm{Gz}$ for one of the groups. Shaffstall and Burton [81] evaluated different anti-G suits. They reported increases of relaxed $\mathrm{G}$ tolerance from below $3 \mathrm{Gz}$ to well over $6 \mathrm{Gz}$ for all set-ups. A noticeable increase in relaxed $G$ tolerance with PPG was also confirmed by Shubrooks [83] and Pecaric et al. [76]. In addition, it was found that G-level tolerance was not diminished when no chest counterpressure was used $[10,58]$.

Sharma [82] observed an increase in relaxed gradual onset run tolerance when PPG was administered, whereas the mean straining gradual onset run tolerance was not different when either PPG or no PPG was administered.

\section{Comparison of AGSM with PPG}

AGSM and PPG were found to be similar in that they both produce intrathoracic pressures of comparable degree which augment cardiovascular pressure, most importantly head-level blood pressure for brain perfusion. Regardless of whether PPG was used or the pilot executed a maximal AGSM, intrathoracic pressures reached up to 70 to $100 \mathrm{mmHg}[16,70]$. According to Burns [21], the basic difference between these two pressure sources is that the AGSM is an active, fatiguing process which pressurizes the lung parenchyma from without, by respiratory muscle activity, whereas PPG is a passive process which pressurizes the lung parenchyma from within through the face mask and the trachea.

When executing an AGSM, pilot fatigue occurs faster $[40,83]$. Surprisingly little pilot fatigue was reported with a novel concept of an anti-G suit that does not rely on PPG [96].

The $+\mathrm{Gz}$-intensity tolerance results of straining and PPG combined and a maximal AGSM alone were found to be comparable $[16,32,83]$. Consequently, the arterial blood pressures were comparable and the $+\mathrm{Gz}$-intensity tolerance with PPG was shown to be not superior to the $+\mathrm{Gz}$-intensity tolerance with a properly executed maximal AGSM.

With respect to G-time tolerance, an increased endurance during simulated aerial combat maneuvers (SACM) was reported by Sharma when using AGSM and PBG simultaneously compared to using AGSM alone [82].

\section{Comparison of PPG alone with PPG in combination with AGSM}

A lot of work on this topic was done in the Swedish Air Force. They found out that PPG contributes to the arterial blood pressure response only to a tiny degree in the presence of a strong AGSM [37], that intrathoracic pressure did not add for AGSM and PPG $[15,16,38]$ and that G-level tolerance was not increased by the combination of PPG and AGSM, whereas G-protective properties of an anti-G suit are further enhanced by pressure breathing [38]. Furthermore, inflation of the counterpressure vest did not seem to reduce "work of breathing" (WoB) at high Gz loads compared to AGSM [59]. In addition, several indications of inadequate support from thoracic counterpressure could be found [16,59]. Contradictory results were presented by Balldin et al. [10]. 
In their experiments, the combination of PPG and an AGSM enhanced $G$ tolerance and comfort of their subjects when compared to AGSM alone.

Also, Clere et al. [32] found hints of an additional benefit when AGSM and PPG were combined. Sharma described PPG as a useful assistance adjunct to AGSM. It makes inspiration effortless and thereby reduces fatigue [82].

\section{PPG Schedules}

\section{PPG schedule per se}

In order to compare PPG schedules, it is necessary to differentiate between the PPG onset pressure and rate or PPG start- and endpoints but also between the respective parameters for the anti-G suit. The ratio between PPG pressure and suit pressures, as well as the torso coverage of the jerkin providing the chest counterpressure, (i.e. assisted PPG) are other important parameters describing the system. All these factors influence the outcome that the use of PPG will have on the pilot.

As an example, the data of the COMBAT EDGE and of the AEA used in the Eurofighter are given below:

- COMBAT EDGE: The system is automatically activated at $+4 \mathrm{Gz}$. Breathing pressure increases by $1,6 \mathrm{kPa}(=12 \mathrm{mmHg})$ with each $+1 \mathrm{Gz}$ increase, up to a design maximum of $8.0 \mathrm{kPa}$ $(=60 \mathrm{mmHg})$ at $9 \mathrm{Gz}$. Chest counterpressure is applied at the same level as mask pressure.

- AEA: Like the COMBAT EDGE, this system also initiates PPG at $4 \mathrm{Gz}$. The mask cavity pressure increases by $1.5 \mathrm{kPa} / \mathrm{Gz}$, reaching $8 \mathrm{kPa}$ $(60 \mathrm{mmHg})$ at $9 \mathrm{Gz}$. PPG is balanced as well.

What is also comparable to the COMBAT EDGE is the pressurization of the suit itself. Pressurization starts at $2 \mathrm{Gz}$ and ends at $9 \mathrm{Gz}$ with a pressure of $70 \mathrm{kPa}$ (about $525 \mathrm{mmHg}$ ). This translates into a rate of $10 \mathrm{kPa} / \mathrm{Gz}$.

Most studies have reported PPG values of 30-60 $\mathrm{mmHg}$; however, there are studies that used lower values $(25 \mathrm{mmHg})[12,14,30,76,83]$, or higher values (up to $80 \mathrm{mmHg}$ ) $[1,6,19,28,42,45,48,76]$. When pressures higher than $60 \mathrm{mmHg}$ are used, the discomfort caused to the aircrew usually outweighs the positive effects of PPG $[1,42,48]$.

$A$ variety of studies investigated the ideal PBG pressure/G schedule and the G level for PPG to cut in and out $[14,33,76]$.

Several authors demonstrated Gz-protection to be improved with increasing PPG pressure $[45,76]$. Depending on the aircraft type, the onset for the application of PPG pressure was reported to be between $3 \mathrm{Gz}[76,77]$ and $4 \mathrm{Gz}[37,66]$.
Also, the ratio of mask-to-pants/anti-G suit pressure was shown to influence the overall effectiveness $[28,33,62,74]$. Ratios between one $[74,91]$ and all the way up to four $[1,48,51,81]$ were systematically studied. In the Aircrew Equipment Assembly (AEA BAeS), it is about 8.75 at $9 \mathrm{Gz}$. The best level of protection was provided by a ratio of $\mathrm{G}$-suit pressure to breathing pressure of about 4:1 [1,50,62].

In an earlier study [77], a pressure of up to 470 $\mathrm{mmHg}$ was applied to the anti-G pants. Up to $60 \mathrm{mmHg}$ were used for PPG. This study, as well as others (e.g. [30]), showed a correlation between PPG pressure and arterial blood pressure.

ACKLES et al. [1] as well as Shaffstall and Burton [81] compared British, Swedish and Canadian systems. The system that provided the best protection against the adverse physiological effects of positive pressure breathing was a jerkin providing the torso coverage of the RAF jerkin and with the $G$ suit inflated to 3.2 times breathing pressure.

\section{Response time of the anti-G gear and work of breathing}

Clère et al. [32] cited a study of Burton investigating delays in the application of appropriate breathing pressure. Delays of up to one second after reaching a $\mathrm{G}$ plateau were stated as acceptable for pilots when executing a mandatory proper AGSM in addition to PPG to compensate for this. He concluded that PPG does not directly protect subjects against the risk of G-LOC.

In today's fighter aircraft capable of high G-onset rates, the known delays can amount to a noticeable fraction of time spent in SACM. Also, the experienced delays account for the increased differential pressure and work of breathing (WoB) causing more-than-necessary pilot fatigue and increased risk of G-LOC because of the required compensating AGSM.

Since the last reviews, the question of the response time and WoB has been explicitly addressed in a technical paper [13]. Modern, electronically controlled regulators reduce the WoB significantly; however, they still have room for improvement.

Krock et al. [66] reported that, in an effort to reduce physiologically undesired effects, reduced pressure schedules were tested on different extended coverage anti-G suits. The experienced reduction in G-protection was well below operational requirements and likely not significant for operations.

Grönkvist et al. [59] presented data showing that a reduction and even an elimination of chest counterpressure did not increase $\mathrm{WoB}$ at any $\mathrm{G}$ load. Likewise, neither $\mathrm{G}$ tolerance nor G-endurance was reduced in any practical way. 


\section{Operational Considerations}

The best of concepts for G-protection do not succeed in service if unwanted or adverse side effects of the anti-G equipment render its use undesirable. Hence, operational considerations must also be taken into account.

\section{Leaks}

In the context of anti-G protection gear as used in this paper, the term "leaks" refers to leaks between the mask and the pilot's face. When the mask shifts for whatever reason, air may be leaking out. Depending on the type of controller used in a specific set-up, this could lead to a drop in applied pressure, which in turn translates into reduced G-protection [78].

Also, the air may be leaking out towards the eyes of the pilot [78]. This is perceived as very uncomfortable [72]. Leaking air may also cause additional noise [78], making audio communication more difficult.

\section{Voice communication}

The search process described above did not reveal any systematic work related to voice communication and PPG. It should, however, be noted that increased respiratory pressure (PPG) does seem to decrease the ability for clear voice communication [72]. This too was one result of a comparative study performed in the German Air Force between optimized variants of the Libelle G Multiplus ${ }^{\oplus}$ and the Aircrew Equipment Assembly [86]. Decreased communication capability can be perceived as a risk to the safe conduct of the mission.

\section{Thermal Stress}

With advancing anti-G suits, reports of thermal stress for the pilot came up. Increasing coverage by the anti-G suit's tight fabric restricts the body's ability to regulate the temperature.

Balldin et al. [7,9] reported that, in a controlled environment, heat stress was comparable for the Combat Edge and a standard US Air-Force anti-G ensemble (without a counterpressure vest). Relaxed $\mathrm{G}$ tolerance, determined in a gradual onset run, decreased after exposure when heat stress, quantified by the body core temperature, increased. Values dropped from $7.6 \mathrm{Gz}$ to $7.1 \mathrm{Gz}$ for the Combat Edge and 7.1 Gz to $6.3 \mathrm{Gz}$ for the standard ensemble. However, PPG did increase $\mathrm{G}$ tolerance, even after some dehydration due to heat stress.

\section{Physical training}

One of the benefits of PPG is the reduction of fatigue of the pilot due to AGSM. To prove this, the heart rate recovery quantified with the help of the "Erholungspulssumme EPS" (the sum of all heart beats over the resting level during the recovery period) was determined after $G$ exposure to +6 and $+8 \mathrm{Gz}$ in a group performing an M-1 maneuver or PPG respectively [23,24]. It could be shown that the fatigue developed by persons using PPG at $+8 \mathrm{Gz}$ was comparable to the fatigue developed by a group performing an M-1 AGSM at $+6 \mathrm{Gz}[23,24]$.

Pilots performing better in aerobic endurance and anaerobic power are less in need of the supportive PPG or advanced anti-G suits. Already in 1974, Burton et al. $[23,24]$ pointed out the increasing importance of physical training as one of the anti-G measures. Russia was reported to successfully take the route of very specific physical training and evaluation [25].

It became obvious during a study the authors were involved in that, aside from developing the appropriate physical strength and endurance, it is of great importance that the proper AGSM required for different anti-G ensembles and/or working principles - pneumatic vs. hydraulic - are practiced to the point where they become second nature.

\section{Cognitive Performance}

Modern anti-G suits protect well against sustained acceleration and enable better G-endurance. They use PPG as well as higher body coverage. Albery and Chelette in 1998 [2] studied the cognitive performance of subjects using five different configurations of anti-G suits. Six subjects performed simulated flying tasks consisting of a primary target tracking task and a secondary task, which was a choice reaction time task called "RAPCOM = Rapid Communication". As a result, it could be shown that subjects wearing anti-G suits using PPG and providing higher coverage were able to perform more efficiently.

\section{Health considerations}

The ultimate objective of all research on $\mathrm{G}$ tolerance and anti-G suit design is to increase both the G-level and the G-endurance tolerance of the pilots to values at least matching, if not exceeding the capabilities of the aircraft flown. As of today, a $\mathrm{G}$ tolerance of up to $9 \mathrm{Gz}$ in operational settings can be achieved through a number of different anti-G suits (e.g. AEA, COMBAT EDGE, ATAGS, the Swedish TFCS (Swedish Tactical Flight Combat 
Suit), ECGS of the Finnish Air Force, the French ARZ 825 AGT system and so on).

However, a number of phenomena with potentially adverse immediate as well as long-term effects on pilot performance and pilots' health has generally been reported as "side effects" so far. Only a few publications pointed out these "side effects" as an objective for further investigation $[14,42,72,78,85]$. It may be worth an attempt to group and review those effects.

\section{Effects on the cardiovascular system}

The increase of intrathoracic and the resultant corresponding rise of systolic, diastolic, and systemic mean arterial blood pressures is one of the key effects of PPG. And this was indeed consistently shown in the literature beginning in 1946 $[1,6,20,21,48,50,51,63,83,98,100]$. Shubrooks [83] measured eye-level systemic arterial blood pressure (Psa) and demonstrated the effectiveness of PPG in maintaining an elevation of Psa during $+G z$. Despite the significant increase in the heart rate and total peripheral resistance due to PPG, a reduction in stroke volume and cardiac output, as well as venous return to the heart, was observed $[1,6]$. All these effects seen were directly related to the level of PPG $[1,6]$. Simultaneous counterpressure did not reveal further hemodynamic effects [6].

Data presented by Goodman et al. [50] demonstrated that cardiovascular responses to PPG are determined not only by the absolute level of PPG but also by G-suit coverage: The higher the PPG level and the coverage of the anti-G suit used, the higher the systolic, diastolic and mean arterial blood pressure reactions to PPG. This was explained by the preservation of the left ventricular preload with extended coverage anti-G suits during PPG. When investigating cardiovascular responses to $+1 \mathrm{Gz}$ PPG under different aspects, Goodmann et al. $[48,51]$ also found that an extended coverage as it is provided by the Tactical Life Support System (TLSS) minimizes cardiovascular function decay observed in other PPG ensembles [48] and permits the use of higher levels of PPG [49]. This has been thought to be due to the augmented venous return and stroke volume resulting from the larger and more uniform application of pressure in the leg G-suit bladders.

In addition, they could demonstrate that, at least for the ATAGS anti-G suit, even reduced suit pressures sufficed to compensate for the adverse cardiac effects of PPG and that a suit pressure being too high may cause an unwanted reduction of the heart rate [51]. However, one also has to take into account that greater coverage of anti-G suits may suppress the cardiovascular reflexes normally triggered by the fall in stroke volume and thus prevent any compensatory increase in the heart rate [42].

Njemanze et al. [74] studied the effects of PPG on the perfusion of the visual cortex and demonstrated that the mean cerebral blood flow velocity (MCBFV) increased in direct proportion to the increase in $+G z$ acceleration with PPG.

Siitonen et al. [84] found that up to $+6 \mathrm{Gz}$ total as well as local cerebral blood flow, although about one-third below the baseline, determined before the onset of acceleration, is maintained sufficiently high by both extended coverage $\mathrm{G}$-suits with PPG and AGSM.

It was reported that, when switched from zero to $1 \mathrm{Gz}$ conditions, the collapse of the internal jugular vein can be avoided by the application of PPB of $30 \mathrm{mmHg}$ or higher. Hence circulation is re-established; the change in posture is compensated [30].

The question whether or not chronic exposure to high-G plus PPG with transient, i.e. repeated and short-term increases of cardiac preload and afterload, would result in right or left ventricular distention or hypertrophy or other long-term adverse effects on the heart has not been exclusively answered yet. Experimental data gained from instrumented animal models did not support these assumptions [64,92]. Albery et al. [3,4] conducted a longitudinal study on 18 subjects without a previous history of high $+\mathrm{Gz}$ exposure and did echocardiography to look for cumulative long-term effects of $\mathrm{Gz}$ exposure times. He described no significant differences for any of the 16 echocardiographic parameters, including right and left ventricular dimensions and wall thickness, aortic and left atrial dimensions and tricuspid and mitral valve inflow velocities after exposure durations described as equivalent to 3 years of F-16 flying. Further, he described no differences between male and female subjects [3].

Balldin et al. [8] tried to answer the question whether PPG in combination with extended coverage anti-G suits would increase the risk for premature ventricular contractions. No signs of premature ventricular contractions occurring more often during the $+\mathrm{Gz}$ plus PPG condition were found in any of the 14 volunteers of their study [8].

\section{Effects on the respiratory system}

Even without any additional $\mathrm{Gz}$ load $(\mathrm{Gz}=1)$, there already exists a ventilation-perfusion mismatch in the lung. Upper regions of the lung are better ventilated and less well perfused; basal re- 
gions are well perfused and experience lesser ventilation. It is in part for this mismatch that the gas exchange in the lung is not ideal. High Gz loads stretching the hydrostatic column dramatically increase this preexisting mismatch between ventilation and perfusion in the lung tissue and the vertical non-uniformity of blood flow $[23,24,41]$. This mismatch together with concomitant mechanical distortion and organ displacement results in an increase in the respiratory dead space in the lung, an overall reduced capability for gas exchange and a reduced $\mathrm{SaO} 2$. Ultimately, this limits the performance of the pilot $[23,24,41,46,47]$.

In the basal regions of the lung, poor ventilation and high perfusion along with increased PPG-induced $\mathrm{O} 2$ partial pressure increase the likelihood of the occurrence of atelectasis on a regular basis. This effect becomes more pronounced with increasing $\mathrm{FiO} 2$, resulting in a further increased O2 partial pressure $[61,89,90,91]$. Reports about dry cough were found in the literature [91]. Atelectasis was shown to be reduced by a dilution of the inspired oxygen concentration by argon or nitrogen, using unassisted positive pressure breathing of $30 \mathrm{mmHg}$ or AGSM [89]. In experiments performed by Haswell et al. [61], no reduction of atelectasis could be found when argon (5\%) was added to pure oxygen. However, a reduction of atelectasis was observed in subjects performing a simulated aerial combat maneuver and breathing $100 \%$ oxygen when PPG of $30 \mathrm{mmHg}$ was used.

The lung seems to be the weakest part of the organism with respect to its reactions to high accelerations in z-direction [88]. Wood et al. therefore called it the "Achilles heel" [99]. Without a doubt, positive pressure breathing puts additional stress on the respiratory system and, as a result, safety concerns have been raised about lung over-distension and subsequent lung pathology. In an attempt to address some of these concerns, Green [55] investigated changes in lung volume subdivisions under high Gz acceleration and PPG with and without full coverage anti-G trousers and varying areas of chest counterpressure coverage. The profound reduction of vital capacity found to occur despite the presence of PPG $(65 \mathrm{mmHg}$ at $+9 \mathrm{Gz}$ ) and variation of chest counterpressure coverage with increasing $+\mathrm{Gz}$ acceleration were most striking. The unchanged expiratory reserve volume (ERV) to vital capacity (VC) (ERV/VC) ratio at $+9 \mathrm{Gz}$ compared to $+1 \mathrm{Gz}$ was used to argue against lung over-distension under these experimental conditions.

In a non-PPG environment, inspiration is an active process, whereas exhalation is passive. The application of PPG reverses this and creates a new respiratory pattern [44]. The pilot has to make an effort to exhale. This, in relation to the level of PPG, was reported to be burdensome, getting more and more difficult, and to be responsible for the fatigue observed due to PPG. It takes some getting used to and training by the pilot $[1,12,44,87]$.

In unassisted pressure breathing, the midposition of the chest (the point at the end of a normal expiration), as well as the minute ventilation and tidal volume, were reported to be much higher than when assisted positive pressure breathing was used [12,87]. A concomitant increase of functional residual air possibly indicates a relatively inefficient mixing of gases in the lungs.

The so-called "assisted or balanced" positive pressure breathing method using an additional counterpressure provided to the chest via a jerkin or a counterpressure vest was introduced to counter-balance any increased pressure in the lungs. It should limit lung expansion and, by doing so, prevent over-distension [12] and was shown to assist expiration, improve comfort and reduce the fatigue involved in unassisted pressure breathing due to the enhanced effort required to exhale against continuous PPG [14,62,81]. For a long time, balanced PPG was also thought to reduce the risk of lung disruption due to high breathing pressures. However, Grönkvist et al. [58] found the chest bladder to be incapable of countering the overall expansion of the lung during PPG and also found the risk of lung parenchyma disruption not being increased when no chest counterpressure was used [58]. In this paper, they were unable to exclude the possibility of balanced PPG being capable of preventing regional over-distension of alveoli located in the apical parts of the lung [58]. Later on [59], Grönkvist's group could show that transpulmonary pressure at the upper portion of the lung was unaffected by pressurization of the chest bladder and concluded that the bladder in the jerkin is not capable of preventing regional over-distension of alveoli located in the apical parts of the lung and does not seem to reduce the risk of lung rupture.

Due to the fact that high PPG pressure is applied in combination with and to compensate the adverse effects of high $\mathrm{Gz}$ accelerations, it is not unexpected for the two effects, high Gz accelerations and PPG, to partially cancel each other out. Borges et al. [27] applied an imaging technique to subjects under $\mathrm{G}$ load. Despite the limitations of the electrical impedance tomography (EIT) method, he describes evidence for atelectasis at $\mathrm{G}$ loads not exceeding $3.5 \mathrm{G}$. The extent of at- 
electasis varied with the fraction of inspired oxygen. Since pressurization of anti-G suits could be shown to provoke augmented intraregional ventilation inhomogeneity, in particular within the lung bases [60], automated inflation of the anti-G suit may have influenced the results.

Data from the literature was found emphasizing that not only the absolute values of PPG but also the anti-G suit design are important for the maintenance of pulmonary function. Comparing the effect PPG had to preserve lung volumes under various anti-G suit pressures and coverages, Tripp and Larssen [93] found out that especially the size of the abdominal bladder is crucial for the $\mathrm{G}$ protection provided by the suit. Therefore, they recommended the use of pulmonary function testing as a useful means of designing and evaluating the next generation of anti-G suits.

Even though PPG set-ups differ in various anti-G suits over some range, newer anti-G systems typically cause relatively high pressures to be applied to the lung (up to 60 to $80 \mathrm{mmHg}$ ). These pressures exceed the commonly accepted standards for clinical ventilation ( 30 to $35 \mathrm{cmH} 2 \mathrm{O}$; equivalent to about 22 to $26 \mathrm{mmHg}$ ) as they can be found in standard textbooks. The same holds true for home ventilation devices (Constant Positive Airway Pressure or (PAP) used to treat sleep apnea $(20 \mathrm{mmHg})$. The standard for mobile ventilation equipment (DIN EN 794-3) defines a stringent upper limit of $60 \mathrm{cmH} 2 \mathrm{O}+10 \%$ (equivalent to about $45 \mathrm{mmHg}+10 \%$ ) which a ventilator must not exceed under any circumstances. These standards reason with the risk of barotraumas.

Although positive pressure breathing for $+\mathrm{Gz}$ protection in the flying community is applied for much shorter times than positive pressure breathing in the clinical setting, the high onset rates and in particular the absolute values of the pressures used give cause for concern [43,55,88,100]. High onset rates can generate significant shear forces in the lung tissue. Both high onset rates and high absolute pressures can result in alveolar ruptures, with bulla formation, potentially leading to pneumothorax, pulmonary interstitial emphysema (PIE) or pneumomediastinum. This indeed happens and has been reported in the literature. There have repeatedly been case reports of sudden, not really satisfactorily explainable pneumothorax events in fighter pilots $[11,43,68,79,94,100]$ or in subjects of positive pressure breathing experiments $[52,53,100]$. Already in 1946, Carr and Essex [29] applied continuous positive pressure respiration of $20 \mathrm{~cm}$ of water to dogs for three hours and found numerous emphysematous blebs beneath the pleura scattered diffusely over both lungs. Krock [64] reported the failure of unprotected lungs in animal models to be between $60-100 \mathrm{mmHg}$ (range of $40-100 \mathrm{mmHg}$ ] "due to alveoli "stretching away" from the inelastic pulmonary vascular sheath".

Even if some authors state that studies on miniature swines could show that medical concerns about elevated transmural and differential pressures in the heart and lung with PBG are without any physiologic basis [26], the reported findings would, in our opinion, give reasons to assume adverse long-term effects of PPG on the lung. Apparently, long-term adverse effects have attracted little investigation so far. Few publications [88] were found regarding long-term effects of high-Gz load on the respiratory system. No publications were found regarding long-term effects of PPG on the respiratory system. There is still a lack of knowledge regarding this topic [85] and systematic studies using sensitive technology such as low-dose CT scanning to address the potential concern regarding pulmonary function have not been done so far [52]. Bang et al. [11] answered the question whether we would be able to detect potential pulmonary pathologies such as emphysema at an early stage by using those methods routinely and commonly applied in today's diagnostics during annual flight medicals. The answer was negative. In their paper, all eight subjects with emphysema and two subjects with lungs cysts detected in the low-dose chest computed tomography were cleared because they revealed normal pulmonary function.

\section{Pain}

The hydrostatic pressure caused by the acceleration forces leads to pain sensations in the dependent regions of the body. Since the arms are actually unprotected in pneumatic anti-G suits, the most known pain is arm pain. There are a number of publications addressing arm pain $[37,56,57,72,75,91]$ for pneumatic anti-G suits. They unanimously described arm pain as an issue.

Travis described arm pain as not limiting in the operational environment for F15 and F16 aircraft. Paul dedicated his work to abdominal and foot pain. He concludes that inflation limiters and foot bladders are needed to eliminate or at least attenuate the pain experienced. There are correlations between forearm venous pressure (FVP), $G$ load and duration and arm pain experienced [56] with venous pressures beginning from 160 to 
$200 \mathrm{mmHg}$. PPG directly raises venous pressure; raising the arm closer to heart level is an option to lower venous pressure [37].

Arm cuffs raise a number of operational issues, which are to be considered carefully. Green 2007 presented a detailed view of the origin of arm pain. He attributed arm pain to forearm venous resistance (FVR) rather than to FVP. PPG was reported to add to arm pain only when arm pain already occurs; when the arm was not close to the hydrostatical height of the heart, its reference position, PPG did increase arm pain.

Welsch et al. covered a novel anti-G suit concept, which is based on hydrostatic rather than pneumatic pressure [96]. It was stated that, with these anti- $G$ suits tested up to $G$ loads in excess of $10 \mathrm{Gz}$, arm pain does not occur at all, likely because the arms are protected as well.

\section{Further effects}

Intraocular pressure was reported to rise with increased arterial blood pressure. This, along with the already positive intraocular pressure compared to the blood pressure of the retinal vessels, helped to protect the retina from rising arterial pressure caused by PPG. Up to PPG pressures of 60 $\mathrm{mmHg}$, no intraocular hemorrhage was observed [54]. Ryles et al. stated in 1996 that it is unlikely that increased intraocular pressure is of medical concern [80].

\section{CONCLUSIONS}

PPG is an integral part of today's anti-G measures. It supports the pilot in tolerating high $\mathrm{G}$ loads for longer periods of time. Generally, nations having 4th and higher generation fighter aircraft in service also have anti-G assemblies that successfully assist the pilot in reaching the desired performance.
The primary goal of reaching $G$ tolerance levels sufficient to match high-performance aircraft can be considered achieved. That said, it seems logical and sensible to turn towards what has so far been dismissed in the context of $G$ tolerance in general and PPG in particular.

The focus of more recent as well as future work has to shift to the undesired side effects of PPG. These side effects are to be addressed and reduced; pilot mobility, comfort, and operational effectiveness are to be considered key values of future anti-G system development. Long-term health-related combat readiness shall be considered an asset. Chances are that some issues are not accessible by short-term experimental procedures. They should be identified through an extended annual flight medical using established clinical health screening procedures. Systematic studies using sensitive, low-impact technology, such as low-dose chest CT scanning, should address the potential concern regarding pulmonary function. That anti-G assemblies ought to be designed with the reduction of side effects in mind has already been stated by Ackles et al. in 1978 [1].

One path towards minimizing the undesired side effects of PPG may lead to fundamentally different anti-G suits. These need to be evaluated thoroughly. A first approach resulting in the development of the liquid-filled hydrostatic Libelle $G$ Multiplus ${ }^{\circledast}$ anti-G suit, which does not rely on PPG, failed to pass the final evaluation process after the transfer to a commercial product had been completed. The published and confirmed benchmarking data, however, was rather encouraging, in particular since some of the most nagging side effects (arm pain, impairment of communication, G-measles, PPG) did not seem to show with this system.

There have been further steps in this direction with the introduction of an anti-G system called G-RAFFE. It was tested at an early stage of its development. Initial results are promising.

\section{AUTHORS' DECLARATION:}

Study Design: Eckard Glaser, Hanns-Christian Gunga, Carla Ledderhos; Data Collection: Eckard Glaser, Hanns-Christian Gunga, Carla Ledderhos; Manuscript Preparation: Eckard Glaser, Hanns-Christian Gunga, Carla Ledderhos. The Authors declare that there is no conflict of interest. 
Review Article

\section{REFERENCES}

1. Ackles KN, Porlier JAG, Holness DE, Wright GR, Lambert JM and McArthur WJ. Protection against the physiological effects of positive pressure breathing. Aviat Space Environ Med. 1978; 49(6): 753-8.

2. Albery WB, Chelette TL. Effect of G suit type on cognitive performance. Aviat Space Environ Med. 1998; 69(5): 474-9.

3. Albery WB, Ten Eyck RP, Wolfe M. Female exposure to high G: Echocardiographic evaluation for chronic changes in cardiac function. Aviat Space Environ Med. 1998; 69(9): 857-61.

4. Albery WB. Echocardiographic evaluation of female centrifuge subjects for chronic changes in cardiac function. Aviat Space Environ Med. 1999; 70(6): 561-4.

5. Bain B, Jacobs I and Buick F. Respiratory muscle fatigue during simulated air combat maneuvering (SACM). Aviat Space Environ Med. 1997; 68(2): 118-25.

6. Balldin UI, Wranne B. Hemodynamic effects of extreme positive pressure breathing using a two-pressure flying suit. Aviat Space Environ Med. 1980; 51(9 Pt1): 851-5.

7. Balldin UI, Siegborn J. G-endurance during heat stress and balanced pressure breathing. Aviat Space Environ Med. 1992; 63(3): 177-80.

8. Balldin UI, Tong A, Marshall JA, Regna M. Premature ventricular contractions during $+\mathrm{Gz}$ with and without pressure breathing and extended coverage anti-G suit. Aviat Space Environ Med. 1999; 70: 209-12.

9. Balldin UI, O`Connor RR, Werchan PM, IsdahI WM, Demitry PF, Stork RL, Morgan TR. Heat stress effects for USAF anti-G suits with and without counter-pressure. Aviat Space Environ. Med. 2002; 73(5): 456-9.

10. Balldin UI, O'Connor RB, Isdahl WM, Werchan PM. Pressure breathing without a counter-pressure vest does not impair acceleration tolerance up to 9 G. Aviat Space Environ Med. 2005; 76(5): 456-62.

11. Bang D-H, Lim D, Jeong O-M, Hwang W-S, Jung J-Y and Lim J. Low-dose chest computed tomography as a screening tool: Findings in 536 aircrews. Aviat Space Environ Med. 2012; 83(9): 896-8.

12. Barach AL, Eckman M, Ginsburg E, Rumsey, CC, Korr I, Eckman, I, Besso, G. Studies on positive pressure respiration. I. General aspects and types of pressure breathing. II. Effects on respiration and circulation at sea level. J Aviat Med 1946; (8): 290-320 and 356.

13. Beaumont M, Lejeune D, Isabey D, Marotte H, Harf A, Lofaso F. Positive pressure generation by pneumatic and electronic 02 regulators: a bench experimental evaluation. Aviat Space Environ Med. 1999; 70(8): 812-6.

14. Buick F. +Gz protection in the future - Review of scientific literature. Research report DCIEM No. 89-RR-47. 1989; 22 pp.

15. Buick F, Hartley J and Pecaric M. Maximum intra-thoracic pressure with PBG and AGSM. AGARD-CP-516, 1991 : 7-1 - 7-9.

16. Buick F, Hartley J, Pecaric M. Maximum intra-thoracic pressure with anti-G straining maneuvers and positive pressure breathing during +Gz. Aviat Space Environ Med. 1992; 63(8): 670-7.

17. Bukhtiiarov IV, Golovkina OL, Khomenko MN. Human gas exchange at $+\mathrm{Gz}$ with the use of various anti-g protectors. Aviakosm Ekolog Med. 2004; 38(1): 35-9.

18. Burns JW. Prevention of loss of consciousness with positive pressure breathing and supinating seat. Aviat. Space Environ. Med. 1988; 59(1): 20-2.

19. Burns JW, Balldin UI. Assisted positive pressure breathing for augmentation of acceleration tolerance time. Aviat Space Environ Med. 1988; 59(3): 225-33.

20. Burns JW, Fanton JW and Desmond JL. Hemodynamic responses to pressure breathing during +Gz (PPG) in swine. AGARDCP-516, 1991: 10-1 - 10-5.

21. Burns J.W. G-protection basis/acceleration physiology. AGARD-LS-202, 1995: I-1 - I-10.

22. Burns JW, Ivan DJ, Stern CH, Patterson JC, Johnson PC, Drew WE, Yates JT. Protection to +12 Gz. Aviat Space Environ Med. 2001; 72(5): 413-21.

23. Burton RR, Leverett SD Jr, Michaelson ED. Man at high sustained +Gz acceleration: A review. Aerospace Med. 1974; 45(10): 1115-36.

24. Burton RR, Leverett SD Jr, Michaelson ED. Man at high sustained +Gz Acceleration. AGARD-AG-190, $1974:$ 1-34.

25. Burton RR. Guidelines for a research and development program for high sustained G. Physiologist. 1993; 36(1 Suppl): S-94-S-97.

26. Burton RR and Whinnery JE. Biodynamics: Sustained Acceleration. In: Fundamentals of Aerospace Medicine. Ed. Roy L DeHart, Chapter 9, 231, Williams \& Wilkins, second edition, 1996.

27. Borges JB, Hedenstierna G, Bergman JS, Amato MBP, Avenel J, Montmerle-Borgdorff S. First-time imaging of effects of inspired oxygen concentration on regional lung volumes and breathing pattern during hypergravity. Eur J Appl Physiol. 2014; 17. Oct. 2014 [Epub ahead of print]. 
28. Byrne JA, Lewis RC and Brown TL. The effect of increased full coverage anti-G trouser inflation pressure on the cardiovascular responses to positive pressure breathing. Operational medical issues in hypo- and hyperbaric conditions. RTO MP-062, 2000; 44-1 -44-20.

29. Carr DT and Essex HE. Certain effects of positive pressure respiration on the circulatory and respiratory system. Am Heart J. 1946; 31: 53-73.

30. Cirovic S, Walsh C, Fraser WD, Gulino A. The effect of posture and positive pressure breathing on the hemodynamics of the internal jugular vein. Aviat Space Environ Med. 2003; 74(2): 125-31.

31. Clère JM, Burns JW. Assisted positive pressure breathing: Effects on $+G z$ human tolerance in centrifuge. AGARD-CP-516, 1991: $13-1$ - 13-8.

32. Clere JM, Ossard G, Melchior F. Physiological considerations concerning positive pressure breathing (PBG) during $+\mathrm{Gz}$. Physiologist. 1993 Feb; 36(1 Suppl): S102-5. Review.

33. Coll RM, Venziale PJ, Cammarota J, Sunn HH, Hrebien L. Physiological effects of various G-suit vs positive pressure breathing ratios on + Gz tolerance. Institute of Electrical and Electronics Engineers, IEEE Eng. Med. Biol. 1996; 15: 5-6.

34. Domashuk J. Metabolic consequences of positive pressure respiration during exposure to acceleration. Kosm. Biol. Aviakosm Med. 1983; 17(6): 33-36.

35. Domaszuk J. The application of positive pressure breathing for improving $+G z$ acceleration tolerance. Aviat Space Environ Med. 1983; 54(4): 334-7.

36. Dussault C, Gontier E, Verret C, Soret M, Boussuges A, Hedenstierna G, Montmerle-Borgdorff S. Hyperoxia and hypergravity are independent risk factors of atelectasis in healthy sitting humans: a pulmonary ultrasound and SPECT/CT study. J Appl Physiol 2016; 121(1): 66-77.

37. Eiken $\mathrm{O}$, Kölegård R, Lindborg B, Mekjavic IB, Linder J. The effect of straining maneuvers on G-protection during assisted pressure breathing. Aviat Space Environ Med. 2003 Aug; 74(8): 822-6.

38. Eiken O, Kölegärd R, Bergsten E, Grönkvist M. G protection: interaction of straining maneuvers and positive pressure breathing. Aviat Space Environ Med. 2007; 78(4): 392-8.

39. Eiken O, Bergsten E, Grönkvist M. G-protection mechanisms afforded by the anti-G suit abdominal bladder with and without pressure breathing. Aviat Space Environ Med. 2011; 82(10): 972-7.

40. Fernandes L, Linder J, Krock LP, Balldin UI, Harms-Ringdahl K. Muscle activity in pilots with and without pressure breathing during acceleration. Aviat Space Environ Med. 2003; 74(6 Pt 1): 626-32.

41. Fong KL, Fan SW. An overview of the physiological effects of sustained high $+G z$ forces on human being. Ann Acad Med Singapore. 1997; 26(1): 94-103.

42. Fraser WD, Ackles KN. Cardiovascular responses to very long duration positive pressure breathing. Report No. NAWCADWAR-95035-4.6 1995; 1-19.

43. Fuchs, HS. Idiopathic spontaneous pneumothorax and flying. With particular reference to the etiological role of decreased atmospheric pressure, pressure breathing, increased gravitational forces, and anti-G suit action. Aerospace Med. 1967; 38 : 1283-85.

44. Gagge AP, Allen SC, Marbarger JP. Pressure breathing. J. Aviat Med. 1945; (2): 2-8.

45. Geng XC, Zhan CL, Yan GD, Chu X, Lu X. The protection against $+\mathrm{Gz}$ afforded by pressure breathing with different pressure schedules. Space Med Med Eng. (Beijing). 2000; 13(3): 166-70.

46. Glaister DH. The effects of gravity and acceleration on the lung. AGARDograph 133, 1970.

47. Glaister DH. Pulmonary effects of high-G and positive pressure breathing. AGARD-CP-516, 1991: 6-1 - 6-4.

48. Goodman LS, Fraser WD, Eastman DE, Ackles KN. Cardiovascular responses to positive pressure breathing using the tactical life support system. Aviat Space Environ Med. 1992; 63: 662-9.

49. Goodman LS, Fraser WD, Ackles KN, Mohn D, Pecaric M. Effect of extending G-suit coverage on cardiovascular responses to positive pressure breathing. Aviat Space Environ Med. 1993; 64: 1101-7.

50. Goodman LS, Freeman MR, de Yang L, Hsia TW, Chan J. Increased G-suit coverage improves cardiac preloading conditions during positive pressure breathing. Aviat Space Environ Med. 1994; 65(7): 632-40.

51. Goodman LS, de Yang L, Kelso B, Liu P. Cardiovascular effects of varying G-suit pressure and coverage during +1 Gz positive pressure breathing. Aviat Space Environ Med. 1995; 66(9): 829-36.

52. Gray G. Medical Screening of subjects for acceleration and positive pressure breathing. Introduction, workshop rationale and objectives, occupational medical concerns. In: Gray G, Bateman W, Clére JM, Tachibana S, Nishibe S, Holewijn M, Kowalski W, Wojtkowiak M, Larson PG, Green N, McGowan D. Medical Screening of subjects for acceleration and positive pressure breathing. AGARD-AR-352, 1997. 
53. Gray GW and Bateman WA. The Canadian report. A. Medical screening of acceleration and PPB research subjects. B. Medical occurrences in acceleration/PPB research subjects. In: Gray G, Bateman W, Clére JM, Tachibana S, Nishibe S, Holewijn M, Kowalski W, Wojtkowiak M, Larson PG, Green N, McGowan D. Medical Screening of subjects for acceleration and positive pressure breathing. AGARD-AR-352, 1997.

54. Green ID. Response of the human retinal vessels to positive pressure breathing. Aerosp Med. 1961; 32(5): 407-11.

55. Green ND. Lung volumes during $+\mathrm{Gz}$ acceleration and the effects of positive pressure breathing and chest counter-pressure. J Gravit Physiol. 1994; 1(1): P41-4.

56. Green ND. Arm arterial occlusion cuffs as a mean of alleviating high + Gz-associated arm pain. Aviat Space Environ Med. 1997; 68(8): 715-21.

57. Green ND, Brown MD, Coote JH. Failure of vascular autoregulation in the upper limb with increased $+\mathrm{Gz}$ acceleration. Eur J Appl Physiol. 2007; 100(6): 621-6.

58. Grönkvist M, Bergsten E, Kölegård R, Linder J, Eiken O. G tolerance and pulmonary effects of removing chest counterpressure during pressure breathing. Aviat Space Environ Med. 2005; 76(9): 833-40.

59. Grönkvist M, Bergsten E, Eiken O. Lung mechanics and transpulmonary pressures during unassisted pressure breathing at high Gz loads. Aviat Space Environ Med. 2008; 79(11): 1041-6.

60. Gustafsson PM, Eiken O, Grönkvist M. Effects of hypergravity and anti-G suit pressure on intraregional ventilation distribution during VC breaths. J Appl Physiol 2001; 91(2): 637-44.

61. Haswell MS, Tacker WA Jr, Balldin UI, Burton RR. Influence of inspired oxygen concentration on acceleration atelectasis. Aviat Space Environ Med. 1986; 57(5): 432-7.

62. Harding RM, Bomar JB Jr. Positive pressure breathing for acceleration protection and its role in prevention of inflight G-induced loss of consciousness. Aviat Space Environ Med. 1990; 61(9): 845-9.

63. Jaron D, Moore TW, and Vieyres P. A cardiovascular model of G-stress effects: preliminary studies with positive pressure breathing. AGARD-CP-516, 1991: 17-1 - 17-7.

64. Krock, LP. Aeromedical issues related to positive pressure breathing for +Gz protection. AL-TP-1992-0024, 1993; 1-10.

65. Krock LP, Russell RL, Siegborn J, Balldin UI. Reduced pressure in extended coverage anti-G trousers with assisted pressure breathing. Aviat Space Environ Med. 1994; 65: 287-92.

66. Krock LP, Balldin UI, Harms-Ringdahl K, Singstad CP, Linder J, Siegborn J. Influence of a reduced G-suit pressure schedule on G-duration tolerance using enhanced G-protection ensembles. Aviat Space Environ Med. 1997; 68(5): 403-9.

67. Lauritzsen LP, Pfitzner J. Pressure breathing in fighter aircraft for G accelerations and loss of cabin pressurization at altitude - a brief review. Can J Anaesth. 2003; 50(4): 415-9.

68. Lin Y-C, Chiu W-K, Chang H, Cheng Y-L, Chen J-C. Spontaneous pneumothorax in flight as first manifestation of alpha-1 antitrypsin deficiency. Aviat Space Environ Med. 2008; 79(7): 704-706.

69. Lu HB, Zhang LF, Bai J, Liu X, Zhang GP. Mathematical modeling of high G protection afforded by various anti-G equipment and techniques. Aviat Space Environ Med. 2007; 78(2): 100-9.

70. Lyons TJ. Human consequences of agile aircraft. RTO-TR-015, 2001.

71. Lyons TJ, Davenport C, Copley GB, Binder H, Grayson K, Kraft NO. Preventing G-induced loss of consciousness: 20 years of operational experience. Aviat Space Environ Med. 2004; 75(2): 150-3.

72. McCloskey KA, Tripp L, Repperger DW and Popper S. Subjective reports concerning assisted positive pressure breathing under high sustained acceleration. AGARD-CP-516, 1991: 11-1 - 11-6.

73. Morgan TR, Brown CL, Murray MR, Burns JW. Positive pressure breathing for G: evolution and promise. Physiologist. 1992; 35(1 Suppl): S151-4.

74. Njemanze PC, Antol PJ, Lundgren CEG. Perfusion of the visual cortex during pressure breathing at different high-G stress profiles. Aviat Space Environ Med 1993: 64 (5): 396 - 400.

75. Paul MA. Extended-coverage-bladder G-suits can provide improved G-tolerance and high Gz foot pain. Aviat Space Environ Med. 1996; 67(3): 253-5.

76. Pecaric M, Buick F. Determination of a pressure breathing schedule for improving + Gz tolerance. Aviat Space Environ Med. 1992; 63: 572-8

77. Prior A.R.J. The optimization of a positive pressure breathing system for enhanced G protection. AGARD-CP-516, 1991: 14-1 - 14-11.

78. Prior A. Positive pressure breathing for G-protection. AGARD-LS-202, 5-1 - 5-16, 1995.

79. Robb, DJ. Case from the aerospace medicine residents' teaching file. Case H57. Complete spontaneous pneumothorax inflight in an F-16 pilot during a high-G maneuver. Aviat Space Environ Med. 1994; 65(2): 170-2. 
80. Ryles MT, Perez-Becerra JL. The effect of positive pressure breathing for altitude protection on intraocular pressure. Aviat Space Environ Med. 1996; 67(12): 1179-84.

81. Shaffstall RM, Burton RR. Evaluation of assisted positive pressure breathing on $+G z$ tolerance. Aviat Space Environ Med. 1979; 50(8): 820-4.

82. Sharma V. PBG \& AGSM: Experience and challenges. Ind J Aerospace Med 2002; 46(1): 19-33.

83. Shubrooks SJ Jr. Positive-pressure breathing as a protective technique during +Gz acceleration. J Appl Physiol. 1973 Aug; 35(2): 294-8.

84. Siitonen SL, Kauppinen T, Leino TK, Vanninen E, Kuronen P, Länsimies E. Cerebral blood flow during acceleration in flight measured with SPECT. Aviat Space Environ Med. 2003: 74(3): 201-206.

85. Smith CK. High performance flying and effects on pulmonary function. Master thesis University of Oslo, 2014.

86. Stein, M. Vergleichserprobung AEA vs. Libelle. Expertenbefragung. Vorläufiger Bericht 2007; pp 165. unpublished.

87. Stolp BW, Arles SP, de L Dear G, Chimiak JM, Gleaton CH, Mielke LL, Moon RE. Cardiopulmonary responses to pressure breathing. Final technical report AL/CF-TR-1995-0049, 1995: 1-74.

88. Stupakov GP, Vartbaronov RA, Khomenko MN. Effects of chronic exposure of high-sustained + Gz accelerations on pulmonary function. J Gravit Physiol 1994; 1(1): P45-7.

89. Tacker WA Jr, Balldin UI, Burton RR, Glaister DH, Gillingham KK, Mercer JR. Induction and prevention of acceleration atelectasis. Aviat Space Environ Med. 1987; 58(1): 69-75.

90. Tikhonov M.A. Eksperimental'noi Biologii i Meditsiny, 1981; 92 Dec: 663-666.

91. Travis TW, Morgan TR. U.S. Air Force positive-pressure breathing anti-G system (PBG): subjective health effects and acceptance by pilots. Aviat Space Environ Med. 1994; 65(5 Suppl): A75-9.

92. Tripp LD, Bolia S, Cooper J, Albery WB, Marit GB. Chronic physiological effects of positive pressure breathing in a high sustained G environment. AL/CF-TR-1993-0073. 1993; 1-31.

93. Tripp LD, Larsen R. The effects of various anti-G suit pressures and positive pressure breathing on lung volumes as measured by spirometry at +1Gz. AL/CF-TR-1996-0134. 1996; 1-31.

94. Voge VM and Anthracite R. Spontaneous pneumothorax in the USAF aircrew population: a retrospective study. Aviat Space Environ Med. 1986; 57(10 Pt 1): 939-49.

95. Walker TB, Dart T, Morgan TR, Balldin UI. Acceleration endurance with pressure breathing during G with and without a counterpressure vest. Aviat Space Environ Med. 2014; 85(4): 401-6.

96. Welsch H, Albery W, Bles W. Physiological consequences: cardiopulmonary, vestibular and sensory aspects. In: Lyons TJ. Human consequences of agile aircraft. RTO-TR-015, 2001; 49-58.

97. Werchen P, O`Connor R, Albery W, Makley L. Aviation safety in the rapid onset, high-G environment. AFRL-HE-WP-TR-2006-0025. 2006; 1-11.

98. Wood EH and Lambert EH. Some factors which influence the protection afforded by pneumatic anti-G suits. J Aviat Med. 1952; 23(6): 218-228.

99. Wood EH, Hoffman EA. The lungs, “Achilles' heel” of air breathers in changing gravitational-inertial force environments. Physiologist. 1984; 27: 47-8.

100.Wood EH. Potential hazards of high anti-Gz suit protection. Aviat Space Environ Med. 1992; 63(11): 1024-6.

\section{ACKNOWLEDGEMENTS}

The views, opinions, and findings contained in this article are our own and should not be construed as official Polish and German Air Force positions, policies or decisions, unless so designated by other official documentation.

Cite this article as: Glaser E, Gunga HC, Ledderhos C. Physiological Effects and Operational Use of Positive Pressure Breathing for G-Protection. Pol J Aviat Med Bioeng Psychol 2016; 22(3): 18-31. DOI: 10. 13174/ pj ambp. 12.07.2017.03 